\title{
A Self Adjustable FACTS Device and Controller for Distribution Systems
}

\author{
Emre Ozkop ${ }^{1}$, Ismail H. Altas ${ }^{1}$, Adel M. Sharaf ${ }^{2}$ \\ ${ }^{1}$ Department of Electrical and Electronics Engineering, Karadeniz Technical University, Trabzon, Turkey \\ ${ }^{2}$ Sharaf Energy Systems, Inc., Fredericton, Nb, Canada \\ e-posta: eozkop@ktu.edu.tr
}

\begin{tabular}{|c|c|}
\hline & \\
\hline $\begin{array}{c}\text { Keywords } \\
\text { FACTS; Dynamic } \\
\text { Voltage Stabilization; } \\
\text { Distribution System; } \\
\text { Multi-loop Control }\end{array}$ & $\begin{array}{l}\text { In this paper, a FACTS based dynamic switched C-type filter (DSCTF) compensator scheme for } \\
\text { distribution systems is presented with different load characteristics and control strategies. In order to } \\
\text { suppress power quality problems and increase overall energy utilization efficiency; design and digital } \\
\text { realization of the DSCTF consisting of dynamic control strategies are studied. Matlab/Simulink } \\
\text { Software Environment is employed to validate the effectiveness of FACTS DSCTF device. It has been } \\
\text { shown that the proposed FACTS-DSCTF is effective to mitigate power quality and energy utilization } \\
\text { problems as well as in compensating voltage disturbances and current harmonics. }\end{array}$ \\
\hline
\end{tabular}

\section{Dağıtım Sistemleri için Kendinden Ayarlanabilir FACTS Cihazı ve Denetleyicisi}

\section{Anahtar kelimeler}

FACTS; Dinamik Gerilim

Düzenleyicisi; Dağıtım

Sistemi; Çok Döngülü

Denetim

\section{Özet}

Bu çalışmada, dağıtım sistemleri için FACTS tabanlı dinamik anahtarlamalı C-tipi filtre (DSCTF) kompanzatörü, farklı denetim stratejileri ve yük karakteristikleri ile sunulmaktadır. Enerji kullanım verimini artırmak ve güç kalitesi problemlerini bastırmak için dinamik denetim stratejilerini içeren DSCTF nin tasarımı ve dijital gerçekleştirilmesi çalışılmıştır. FACTS DSCTF cihazının etkinliğini doğrulamak için Matlab/Simulink yazılım ortamı kullanılmıştır. Önerilen FACTS-DSCTF in güç kalitesi ve enerji kullanım problemlerini azaltmanın yanı sıra gerilim bozukluklarını ve akım harmoniklerini de kompanzasyonunda etkili olduğunu göstermektedir.

C Afyon Kocatepe Üniversitesi

\section{Introduction}

Every year world energy consumption has increased since the world population has grown and diversity of electrical devices has become bigger than before (EIA, 2016). While requirement of electrical energy have been provided by the different kinds of energy sources such as conventional (coal, petroleum, natural gas, etc.) and renewable (wind, solar, wave, etc.), importance of power electronic converters which are bridge between the electrical source and consumer has become crucial to provide stable, reliable and secure power transmission and distribution system structures (Hingorani, 1995;
Davidson and Preville 2009; Wang er al. 2013; Bindra, 2016).

Consumers and generation unit profiles have caused more power quality problems nowadays than before (Latran et al. 2015). Increasing switched load applications and interfacing low power generating stations to the distribution systems has made power quality problems bigger to solve. Consumers can be named as loads, which can be classified as linear loads (motors, incandescent lamps, etc.) and nonlinear loads (power electronic devices, uninterrupted power supplies, computer, etc.). So harmonics, which can cause voltage distortion, failure of sensitive electronic equipment, equipment overheating, etc, occur on power system (Mazumdar et al. 2007). 
The filters such as passive, active and hybrid types can be employed to minimize the effects of harmonics in the power systems (Peng et al. 1990; Lee et al. 2015; Li et al. 2015). By reason of the fact that the consumer and power distribution system profiles are more variable, nonstationary and dynamic, the filter structure should operate coordinately for variable system operating conditions. Passive filters can be designed for specific harmonic component so that changing system operating conditions decrease effectiveness of passive filters and cause resonances. Active filters are either more appropriate or preferable to be employed in the power system (Busarello et al. 2016; Ozkop et al. 2011).

In this paper, a distribution system consisting of ac hybrid and dc loads controlled by single and multiloop based controllers with FACTS based dynamic switched C-type filter (DSCTF) compensator scheme is discussed. A Matlab simulation model of a sample power system with the FACTS DSCTF with proposed controllers is developed and its effectiveness is well verified by simulation results.

\section{FACTS System Description and Modelling}

The proposed system is shown in Figure 1 with the FACTS based dynamic switched C-type filter (DSCTF) compensator scheme. The system consists of power electronic converters (dc-dc boost and buck converter, $\mathrm{dc} / \mathrm{ac}$ inverter), voltage compensator filter (DSCTF) and loads (uncontrolled and controlled dc loads and linear and nonlinear ac loads). The system parameters are given in Appendix.

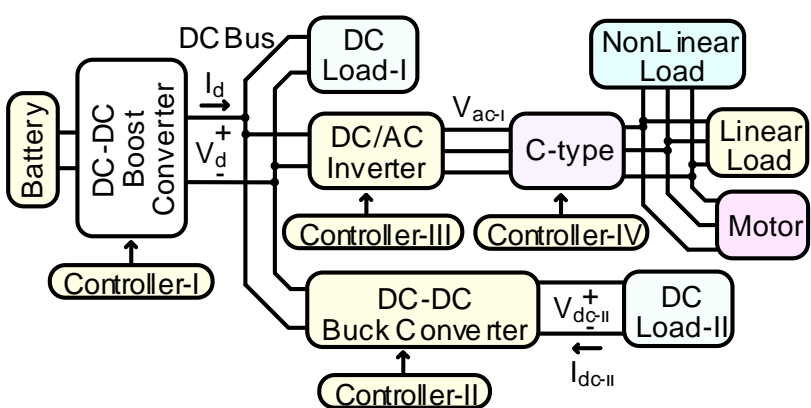

Figure 1. Block diagram of the sample study system with the FACTS DSCTF.

While the power system supplies a hybrid load (residential, commercial and industrial loads), power quality problems such as voltage and current disturbances and harmonics break out. Hybrid load is modeled to analyze power system performance under various conditions. The hybrid load comprises three types of loads such as nonlinear, AC linear and motor loads shown in Figure 2.

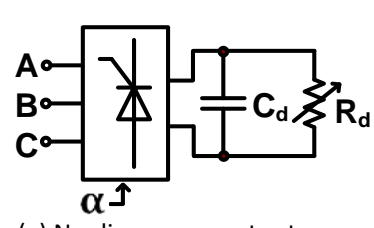

(a) Nonlinear converter type

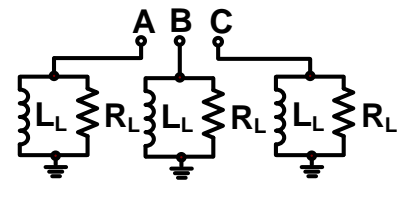

(b) AC linear type

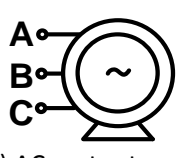

(c) AC motor type

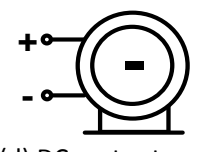

(d) DC motor type (e) DC resistor type

In Fig.2.(a), there is a controlled DC converter type load with variable $R_{d}$ resistor. The variable $R_{d}$ resistor equation is given in Equation (1).

$R_{d}=R_{0}+R_{1} \sin ^{2} \omega_{o 2} t$

The thyristor converter firing angle $\alpha$ is represented in Equation (2).

$\alpha=\alpha_{0}+\alpha_{1} \sin ^{2} \omega_{o 1} t$

In nonlinear load, the thyristor converter generates harmonics and current distortions. In order to mitigate these undesirable effects, a dynamic switched C-type filter (DSCTF) compensator scheme is adapted into the distribution line. The DSCTF is a combination of series and shunt filter structures to enhance power quality of the system.

\subsection{Configuration of the Dynamic Switched C- Type Filter (DSCTF)}

The proposed circuit of the DSCTF shown in Figure 3 is composed of shunt compensation subsystem. Generally, the shunt compensation can be employed to minimize power losses and provide desired voltage levels. The selected parameters of the proposed DSCTF are listed in Appendix. 
An inductance $\left(L_{f}\right)$ in series with capacitors $\left(C_{f 1}, C_{f 0}\right)$ is used to limit the inrush current and active compensators, which comprise shunt capacitors $\left(C_{f 1}, C_{f 0}\right)$, inductance $\left(L_{f}\right)$ and resistances $\left(R_{f 1}, R_{f 2}\right)$ supply the needed reactive power to attenuate harmonics.

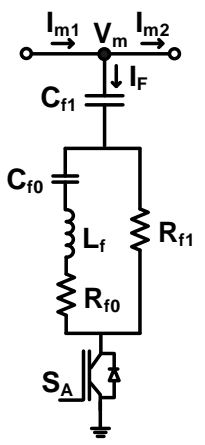

Figure 3. A circuit diagram of the DSCTF.

In this paper, the dynamic switched C-type damped power filter (SCTDPF) compensator scheme proposed in (Ozkop et al. 2011) is also used to determine and compare the performance of the proposed filter topology effectively. The circuit SCTDPF is shown in Figure 4.

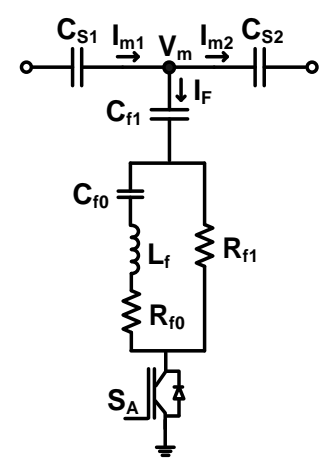

Figure 4. A circuit diagram of the SCTDPF.

As distinct from the DSCTF, the series capacitors $\left(\mathrm{C}_{\mathrm{s} 1}, \mathrm{C}_{\mathrm{S} 2}\right)$ are added in the line in order to increase the power transmission capacity of the system by reducing the effective line reactance

\subsection{Controller Structure}

The power system consists of four controller schemes based on multi-loop and single-loop structures as shown in Figures 5 and 6 .

The block diagram of the proposed controller has a more than one loop structure as shown in Figure 5.a. The controller uses the mutual $A C$ bus voltage $\left(V_{m}\right)$, changes in the mutual $\mathrm{AC}$ bus currents $\left(I_{m 1}\right.$, $\left.I_{m 2}\right)$ and changes in the filter current $\left(I_{f}\right)$ to constitute an error signal for controlling of $A C$ voltage. The scheme does not require reactive power measurement. A low pass filter with time delay $(5 \mu \mathrm{s})$ is employed to eliminate ripples and spikes in voltage and current waveforms.

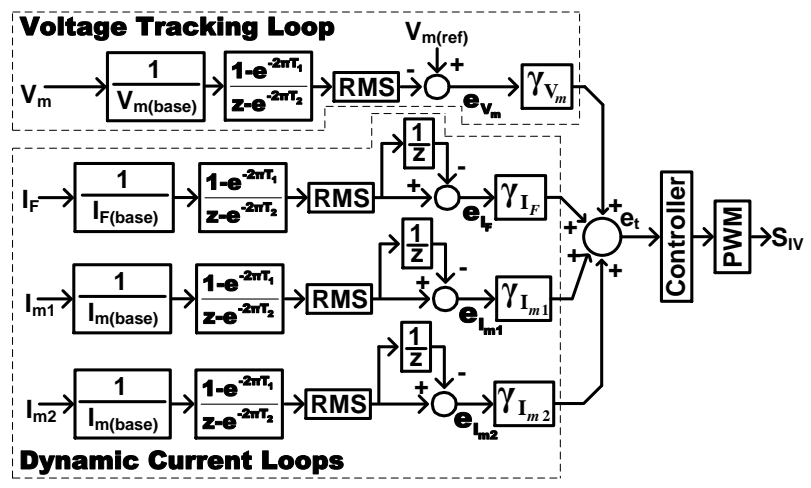

(a) Controller-IV

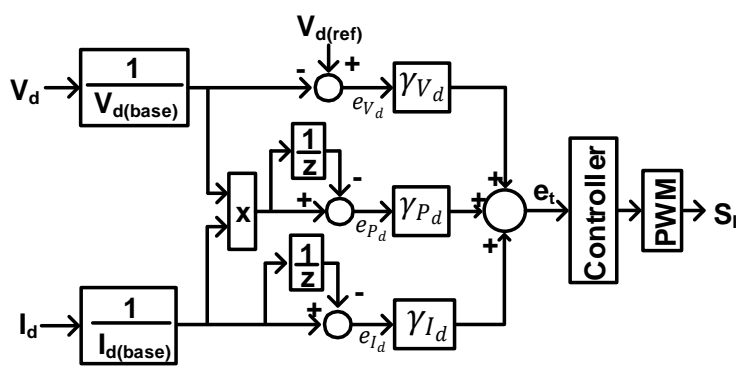

(b) Controller-I

Figure 5. The power system multi-loop control schemes.

The error in mutual $\mathrm{AC}$ bus voltage $\left(e_{V m}\right)$ is a difference between the reference and real values of voltage, but in the meantime error representing changes in mutual $\mathrm{AC}$ bus and filter currents $\left(e_{I_{F}}\right.$, $\left.e_{I_{m 1}}, e_{I_{m 2}}\right)$ are based on differences between the real and delay input values.

The related weighting factors $\left(\gamma_{V_{m}}, \gamma_{I_{F}}, \gamma_{I_{m 1}}, \gamma_{I_{m 2}}\right)$ are used to help user to define control goals clearly such as mutual AC bus voltage or current or filter current controls or hybrid control. Depends on the control goal, the weight factors are increased or decreased. The related weigh factors and errors are multiplied and each multiplication result summated and system common error $\left(e_{t}\right)$ comes out. Thus the controller block uses the error signal to generate an appropriate duty cycle for a pulse width modulation (PWM) block. Switching signal, 
$S_{A}\left(S_{I V}\right)$ is modulated for ON and OFF actions by the PWM block. There are loops based on dc bus voltage $\left(V_{d}\right)$ and current $\left(I_{d}\right)$ and dynamic voltagecurrent $\left(V_{d} \times I_{d}\right)$ in the Controller-I. The control strategies can be modified depending on objectives such as to control dc bus voltage, current or instantaneous dc power flow. The parameters of the dynamic error driven controllers are given in Appendix.

The Controller-II and Controller-III are based on a single-loop control scheme shown in Figure 6. The objective of the controllers tracks the reference voltage trajectory with minimum error. The parameters of the single-loop controllers are given in Appendix.

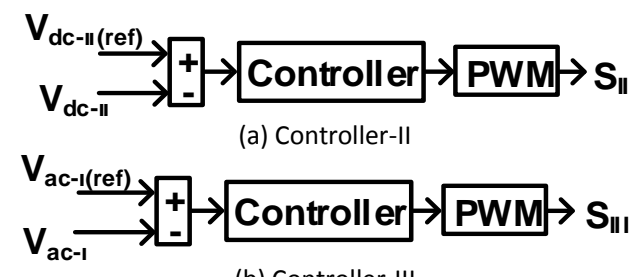

(b) Controller-III

Figure 6. The power system single-loop control schemes.

Demands on controllers are to ensure fast response, less or zero overshoot, zero steady-state error, high stability margin, robustness and provide an increase in productivity by improving quality, and reducing maintenance requirements (Ang et al. 2015). PI controllers preferred in the most of process control applications since it works efficiently in various areas of industry so that a classical PI controller is employed in all control schemes in this study.

Trial-and-error tuning is a technique, which is used widespread in industrial practice to determine the PI controller parameters via observing the dynamic behavior of the system output. The effects of the control parameters on system behavior should be considerably comprehended to perform effective trial-and-error tuning (Wang et al. 2008). After initial guess of the control parameters are assigned, they are modified until a desired system output is observed. The chance of success on determination the controller parameters depend on user's knowledge, skill and experience (Johnson et al. 2005). The trial and error tuning technique is applied in this paper.

\section{Digital Simulation and Results}

The proposed FACTS DSCTF topology with a distribution system is performed in the Matlab/Simulink Software Environment, which is one of the most effective simulation tools. The study system is not tested experimentally in hardware. A conventional PI controller is applied in all controllers (Controller-I, II, III, and IV). While Controller-II and III are based on voltage, Controller-I and IV consists of both current and voltage.

As the constant voltage references are employed for Controller-I, III and IV, the variable references applied through the DC load-II for Controller-II in time remains voltage constant $(100 \mathrm{~V})$ during the first $400 \mathrm{~ms}$, and then transiently decreases, remains $75 \mathrm{~V}$ during $300 \mathrm{~ms}$. At 700th the reference voltage increases instantly the $125 \mathrm{~V}$ and remains this voltage at the end of 1000th millisecond.
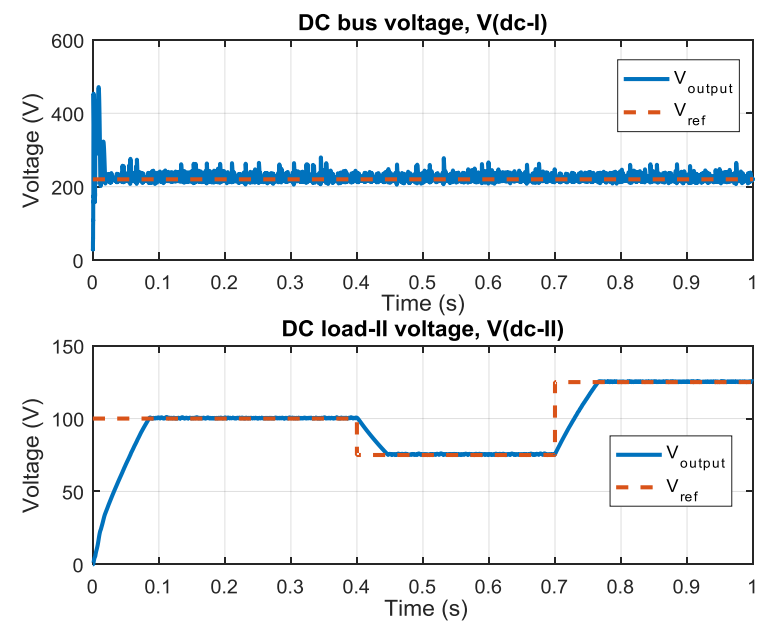

Figure 7. Dynamic responses of the common dc bus and dc load-II (with DSCTF). 

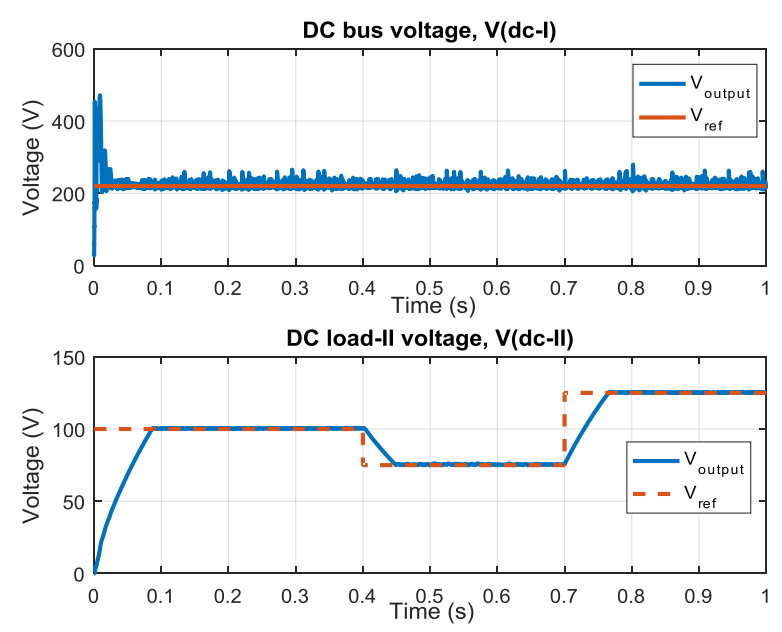

Figure 8. Dynamic responses of the common dc bus and dc load-Il (with SCTDPF).
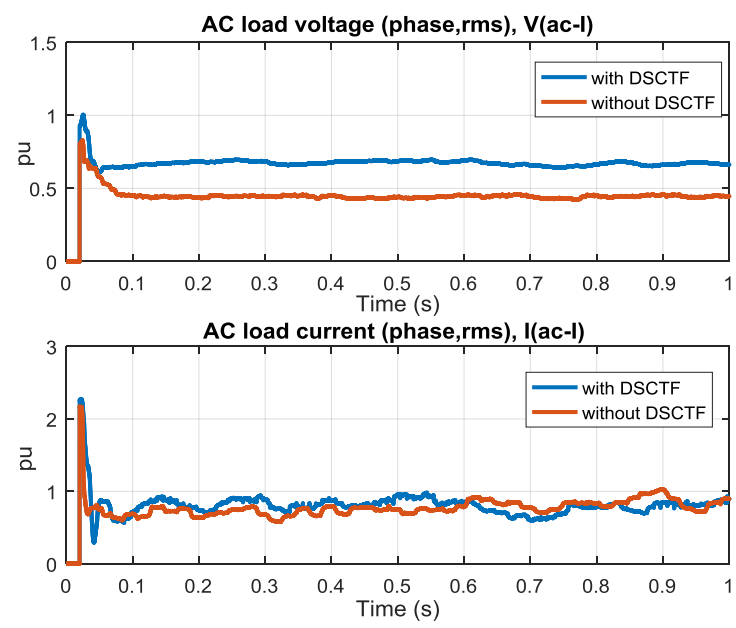

Figure 9. Dynamic responses of the ac load (with DSCTF).
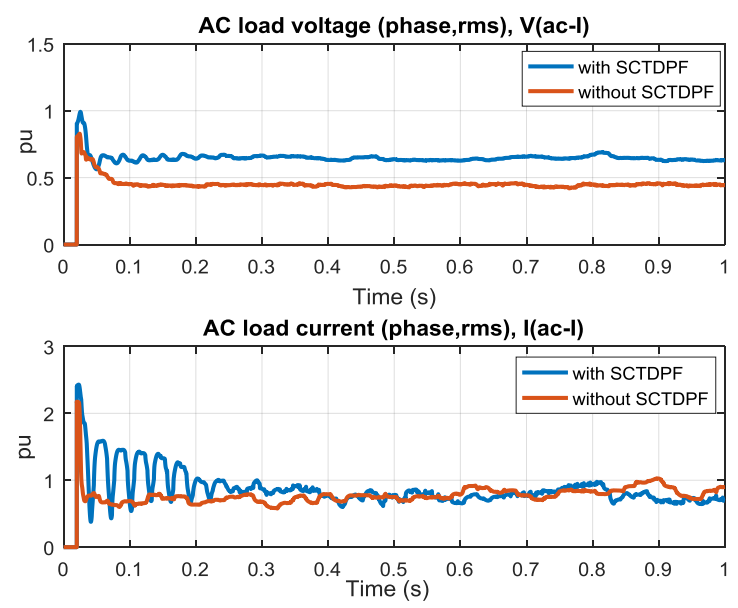

Figure 10. Dynamic responses of the ac load (with SCTDPF).

The performance of the system under different control strategies was evaluated and the results are shown in Figures 7-10.
In this paper, performances indexes, which are integral of squared error (ISE), integral of the absolute error (IAE) and integral of time multiplied by absolute error (ITAE), are employed to make comparison between the controllers and get feedback about the transient and steady-state characteristics of a control system. The performances measurement of controllers with different system topology are given in Table 1 . The meter readings of the system parameters at the $A C$ load side for different filter schemes are tabulated in Table2.

Table 1. The performances measurement of controllers

\begin{tabular}{cccccc}
\hline \multirow{2}{*}{ C-type } & Controller & Controller & \multicolumn{3}{c}{ Performance Indexes } \\
& Number & Type & ISE & IAE & ITAE \\
\hline \multirow{4}{*}{ DSCTF } & Controller-I & PI & 0.8424 & 0.3870 & 0.1434 \\
& Controller-II & PI & 231.7 & 5.201 & 1.570 \\
& Controller-III & PI & 0.1246 & 0.3384 & 0.1646 \\
& Controller-IV & PI & 0.1576 & 0.3424 & 0.1647 \\
\hline \multirow{4}{*}{ SCTDPF } & Controller-I & PI & 0.7968 & 0.3615 & 0.1418 \\
& Controller-II & PI & 274.6 & 6.035 & 1.602 \\
& Controller-III & PI & 0.1425 & 0.3644 & 0.1781 \\
& Controller-IV & PI & 0.1749 & 0.3683 & 0.1782 \\
\hline \multirow{4}{*}{ OFF } & Controller-I & PI & 1.9810 & 0.5390 & 0.1490 \\
& Controller-II & PI & 272.60 & 5.970 & 1.5840 \\
& Controller-III & PI & 0.3155 & 0.5563 & 0.2779 \\
& Controller-IV & PI & ---- & ---- & --- \\
\hline
\end{tabular}

Table 2. Meter readings (mean) of the system parameters at the ac load

\begin{tabular}{ccccc}
\hline C-type & \multicolumn{4}{c}{ System Parameter (in p.u) } \\
\hline & Controller & $\begin{array}{c}\text { Phase } \\
\text { Voltage }\end{array}$ & Current & Real Power \\
\hline DSCTF & PI & 0.6616 & 0.7949 & 1.164 \\
\hline SCTDPF & PI & 0.6359 & 0.5168 & 0.7059 \\
\hline OFF & Without & 0.4436 & 0.7624 & 0.7366 \\
\hline
\end{tabular}

From the results given in Tables 1-2, it is clear that the voltage, current, power improvements are considerably enhanced at the AC load side tested under different filter strategies in the power system.

The proposed FACTS-DSCTF is more effective than the SCTDPF to mitigate power quality and energy utilization problems. 


\section{Conclusion}

The paper presents a digital model and validation study of the simulation results show that the proposed FACTS DSCTF topology with a distribution system. In the distribution system, ac hybrid (residential, commercial and industrial loads) and dc loads are used with novel controllers. The control strategies are based on the related voltage and current of the measurement points.

The dynamic Controller-I, Controller-II, ControllerIII and Controller-IV schemes are mainly used to regulate the dc-dc converters, dc-ac inverter and the proposed FACTS DSCTF topology and also to control power flow from dc power source to dc and ac loads to reduce errors of controllers and to mainly track a given voltage reference trajectory. The simulation results show that the proposed FACTS DSCTF topology with a distribution system has better performance than the system without the topology. The dynamic error trajectory loops based on voltage and current values (Controller-I and IV) ensure effective regulation and operation of load demands.

\section{Reference}

Ang, K.H., Chong, G. and Li, Y., 2005. PID control system analysis, design, and technology. IEEE Transactions on Control Systems Technology, 13(4), 559-576.

Bindra A., 2016. Projecting the evolution of power electronics: Highlights from FEPPCON VIII. IEEE Power Electronics Magazine, 3(1), 32-44.

Busarello, T.D.C., Pomilio, J.A. and Simões, M.G., 2016. Passive filter aided by shunt compensators based on the conservative power theory. IEEE Transactions on Industry Applications, 52(4), 33403347.

Davidson, C.C. and de Preville, G., 2009. The future of high power electronics in transmission and distribution power systems. 13th European Conference on Power Electronics and Applications, 2009, EPE '09, 1-14.

Hingorani, N.C., 1995. Power Electronics: Advances in the application of power electronics in generation, transmission, and distribution systems. IEEE Power Engineering Review, 15(10), 13-13.

Johnson, M.A. and Moradi, M.H., 2005. PID control, new identification and design methods. Springer-Verlag.
Latran, M.B., Teke, A. and Yoldas Y., 2015. Mitigation of power quality problems using distribution static synchronous compensator: a comprehensive review. IET Power Electronics, 8(7), 1312-1328.

Lee, T.L., Wang, Y.C., Li, J.C. and Guerrero, J.M., 2015. Hybrid active filter with variable conductance for harmonic resonance suppression in industrial power systems. IEEE Transactions on Industrial Electronics, 62(2), 746-756.

Li, Y., Liu, F., Saha, T.K., Krause, O. and Cao, Y., 2015. Hybrid inductive and active filtering method for damping harmonic resonance in distribution network with non-linear loads. IET Power Electronics, 8(9), 1616-1624.

Mazumdar, J., Harley, R.G., Lambert, F.C. and Venayagamoorthy, G.K., 2007. Neural network based method for predicting nonlinear load harmonics. IEEE Transactions on Power Electronics, 22(3), 1036-1045.

Ozkop, E., Sharaf, A.M. and Altas, I.H., 2011. An Intelligent Self Adjustable Facts Device for Distribution Systems. International Journal of Power Engineering \& Green Technology (IJPEGT), 2(1), 1126, 2011.

Peng, F.Z., Akagi, H. and Nabae, A., 1990. A new approach to harmonic compensation in power systems-a combined system of shunt passive and series active filters. IEEE Transactions on Industry Applications, 26(6), 983-990.

U.S. Energy Information Administration (EIA), 2016. International Energy Outlook. DOE/EIA-0484(2016), IEA Press.

Wang, P., Goel, L., Liu, X. and Choo, F.H., 2013. Harmonizing AC and DC: A Hybrid AC/DC Future Grid Solution. IEEE Power and Energy Magazine, 11(3), 76-83.

Wang, Q.G., Ye, Z., Cai, W.J. and Hang, C.C., 2008. PID Control for multivariable processes. Springer-Verlag, Berlin Heidelberg. 


\section{Appendix}

Table A1. Sample study system parameters.

\begin{tabular}{|c|}
\hline $\begin{array}{c}\text { Controller-I } \\
K_{P}=10, K_{I}=1, \gamma_{V_{d}}=10, \gamma_{P_{d}}=0.1, \gamma_{I_{d}}=0.1\end{array}$ \\
\hline $\begin{array}{c}\text { Controller-IV } \\
K_{P}=50, K_{I}=10, \gamma_{V_{m}}=1, \gamma_{I_{F}}=1, \gamma_{I_{m 1}}=0.5, \gamma_{I_{m 2}}=0.5\end{array}$ \\
\hline $\begin{array}{cc}\text { Controller-II } & \text { Controller-III } \\
K_{P}=10, K_{I}=0.9 & K_{P}=0.4, K_{I}=500 \\
\end{array}$ \\
\hline $\begin{array}{cc}\text { DC-DC Boost Converter } & \text { DC-DC Buck Converter } \\
L=9.5 \mu \mathrm{H}, \mathrm{C}=4.5 \mathrm{mF}, f_{s}=5 \mathrm{kHz} & L=32.5 \mu \mathrm{H}, \mathrm{C}=0.1 \mathrm{mF}, f_{s}=1 \mathrm{kHz}\end{array}$ \\
\hline $\begin{array}{c}\text { C-type (DSCTF and SCTDPF) } \\
C_{S 1}=C_{S 2}=30 \mathrm{mF}, C_{f 1}=2.5 \mathrm{mF}, C_{f 0}=0.15 \mathrm{mF} \\
R_{f 1}=0.7 \Omega, R_{f 0}=0.1 \Omega, L_{f}=5 \mathrm{mH}, f_{s}=5 \mathrm{kHz}\end{array}$ \\
\hline $\begin{array}{c}\text { DC Load-I } \\
R=9 \Omega\end{array}$ \\
\hline $\begin{array}{c}\text { DC Load-II } \\
L_{m}=80.5 \mathrm{mH}, R_{m}=35 \Omega, \omega_{a-\text { rated }}=500 \mathrm{rad} / \mathrm{s} \\
K_{e}=0.117 \mathrm{~V} . \mathrm{s} / \mathrm{rad}, B_{m}=30 \times 10^{-6}, J_{m}=2 \times 10^{-4}\end{array}$ \\
\hline $\begin{array}{c}\text { Linear Load } \\
P=2.55 \mathrm{k} W, Q=1.58 \mathrm{kVAR}\end{array}$ \\
\hline $\begin{array}{c}\text { Motorized Load } \\
S=2 k V A, V=220 \mathrm{~V}, f=50 \mathrm{~Hz}, R_{s}=0.435 \Omega, L_{s}=4 \mathrm{mH} \\
R_{r}=1 \Omega, L_{r}=2 \mathrm{mH}\end{array}$ \\
\hline $\begin{array}{c}\text { Nonlinear Load } \\
S=2 \mathrm{kVA}, \alpha_{0}=10^{\circ}, \alpha_{1}=30^{\circ}, \omega_{o 1}=15 \mathrm{rad} / \mathrm{s}, \omega_{o 2}=25 \mathrm{rad} / \mathrm{s} \\
C_{d}=825 \mu F, R_{0}=40 \Omega, R_{1}=80 \Omega\end{array}$ \\
\hline $\begin{array}{c}\text { Thyristor Converter } \\
R_{\text {snub }}=500 \Omega, C_{\text {snub }}=0.1 \mu F, R_{\text {on }}=1 \mathrm{~m} \Omega, L_{\text {on }}=0.0 \Omega, V_{f}=0.8 \mathrm{~V}\end{array}$ \\
\hline
\end{tabular}

